\title{
Or.
}

ISSN 2278 - 0211 (Online)

\section{Defining a New Art Coefficient: The Invention of Sublime Art through the Hybridization of Traditional and Contemporary Visual Idioms and Methodologies}

\author{
Clement Emeka Akpang \\ Lecturer, Department of Visual Arts and Technology, \\ Cross River University of Technology (CRUTECH), Nigeria \\ Sukanthy Egharevba \\ Lecturer, Department of Visual Arts and Technology \\ Cross River University of Technology (CRUTECH), Nigeria
}

\begin{abstract}
:
Contemporary art remains arguably the most dynamic phase of human expressionism, as well as the most contested discourse in the humanities. The ambiguity surrounding contemporary art stems from its lack of a unifying ideology, supposed mimicry of established art conventions and lack of originality. This paper questions this construed viewpoint, by rather exploring appropriation and reprise in contemporary art as a form of creative translation defined by Altermodernism. Using stylistic and discourse analysis as methodologies, the works of three contemporary artists George Nuku, Sukanthy Egharevba and Clement Akpang were analysed in terms of their visual configurations, methods and ideologies. Findings indicate that the re-invention of established indigenous pictorial elements and the hybridization of different cultural idioms in Twenty-first Century artistic expressionism leads to the creation of sublime art that defies cultural boundaries and exists in a timeless oscillation between traditionalism and contemporaneity. Rather than constituting mimesis of existing cultural forms, the works of the aforementioned artists foster cultural heritage appreciation and defines a new art coefficient of Relational Aesthetics. It is recommended, therefore, that as contemporary art continues to re-invent itself, a key variant to understanding its multifaceted nature should be to engage in cultural translation and revivalism through art and design framed in the philosophy of Altermodernism.
\end{abstract}

Kevwords: Art, traditional, contemporary, Altermodernism, sublime art, visual idioms, hybridism

\section{Introduction}

Contemporary art is multifaceted, dynamic, innovative and complex and these qualities combine to make art created today arguably the most engaging form of artistic expressionism since the inception of art. Contemporary art is defined as art of the present day and of the relatively recent past, of an innovatory/ avant-garde nature or, as the works of artists who are living in the Twenty-first Century (Tate Modern 2010). This definition reveals a mapping of contemporary art around three distinct features: the immediate, the contemporaneous and the contemporal (Smith 2009: 2). This quest to capture the contemporal and its multitudinous creative possibilities, results in the creation of a plethora of eclectic art genres. This plethora of art genres captures the multifaceted dynamism of contemporary art and the challenge of categorization. The embrace of the contemporal, multiculturalism and multi-disciplinary intersection of genres and disciplines that define contemporary society and culture, coalesce to make contemporary art rather than being a specific movement or ideology, an amalgam of styles, ideologies and creative ethos linked by a shared desire to interrogate and capture contemporary society, culture and technological advancement in the arts. This has led to innovative art forms distinct in qualities and complex in conceptualism that defy all traditional artistic categorization established in art history. This is because artists respond to a new global society/ environment that is culturally diverse, technologically advanced, and politically/ socially chaotic, through their works and the results of such combined influences manifest in new eclectic visual idioms. This is also underpinned by the fact that contemporary artists work with a plethora of new methods, materials, techniques and ideologies to comment on the context of their present time, offering rich resource through which to consider current ideas and rethink the familiar. The resultant effect is contemporary art lacking a uniform organizing principle, ideology or style. Contemporary artists give voice to the varied and changing cultural landscape of identities, values, and beliefs in contemporary society, thus. Cannot be defined 
by a single ideology or stylistic idiom. What this has done is challenge and defy established definitions and categorization of art, thus, drawing viewers into contemplative meaning making by asking questions that deconstruct materiality to reveal inner meanings in art forms.

The complexity of contemporary art with its lack of a unifying philosophy also stems from its skepticism posing questions that destabilizes all known constants in classical civilizations. Contemporary artists question traditional ideas of how art is defined, what constitutes art, and how art is made, while creating a dialogue with and in some cases rejecting the styles established as conventional modes of expression in the arts. According to Terry Smith (2009) "contemporary art has become in its forms and contents, its meanings and usages, thoroughly questioning in nature, extremely wide-ranging in its modes of asking and in the scope of its inquiries" (Smith 2009: 2). As a result, contemporary art emerging from such critical approach to art making with its multifaceted genres conveys diverse ideologies and manifestoes that speak to the dramatic social, political and technological changes of the last 40 years throughout the world; it engages in questioning many of society's values and assumptions especially in the face of such rapid multiculturalism and globalism. Using visual vocabularies of abstraction and representationalism, contemporary artists create distinct works that convey the social and political concerns of contemporary societies. Contemporary art, therefore, serves a host of functions but most significantly as a catalyst for an on-going process of open discussion and intellectual inquiry about the world today, by providing an opportunity to reflect on contemporary society and the issues relevant to ourselves, and the world around us using art as a point of departure for referencing/ interrogating complex societal issues. In this sense what we consider as contemporary art is part of a cultural dialogue that concerns larger contextual frameworks such as personal and cultural identity, family, community, and nationality, politics, economy, and environment as well as hybridism and cultural revivalism etc.

The complexities and diverse innovations that characterize contemporary art and its ardent connections to the political, the cultural, the environmental and technological advancement of contemporary society reflects a new sense of subtle avantgardism best captured in the unique works, eclectic methodologies and stylistic formalisms that constitute the art of many leading artists today. The British artist Banksy for example, elevates the language of graffiti into a new art genre that combines painting, stenciling and graffiti in an eclectic manner that has now legitimated a social crime (wall tagging) into a distinct contemporary visual vocabulary celebrated the world over. In this new contemporary idiom Banksy an all-purpose provocateur finds the ideal idiom to foster his anti-establishment ideals. As he points out, "I like the political edge of art...all graffiti is low-level dissent, but stencils have been used to start revolutions and to stop wars..." (Banksy quoted in EllsworthJones 2013: 2). Banksy's eclectic approach to contemporary art, thus, is inclined towards a contemporary avant-garde framed in anti-establishment sentiments, and the hybridization of art genres. His works captures the failings of global governments and the adversities that results in governments' inadequacies, but also reveals a unique juxtaposition three art genres (graffiti, stenciling and painting) in a unique reflection of genre hybridization that defines contemporary art. Mathias Gmachl and Rachel WingField engage in the creation of contemporary art that bridges the boundaries between art, design, science and the environment. They exhibit a variant of the multifaceted nature of contemporary art by creating forms that reach beyond specialist boundaries. They invent visionary experiences and environments that allow people to dream and re-imagine new visions for the future. Their works capture the present and projects into the future by speculating on near and far future scenarios as a way to probe the social and environmental impacts of emerging biological and technological futures, as well as synthesize living materials with digital tools to communicate relevant scientific and technological concepts in a broader cultural and social context. Unlike Mathias Gmachl and Rachel Wingfield who combine science, art and design to create new environments, the Chinese dissident artist and arguably the most powerful artist living today Ai Weiwei is an embodiment of the eclecticism that defines contemporary art. He produces art that are among the most socially engaged works of art being made by anyone today from erratic streams of materials and methodologies such as installations, photographs, furniture, paintings, books, and films, sculpture, ready-mades etc. Ai's unrelenting audacity and imagination have thrust him into a far more prominent role, as China's leading innovator of provocation. Ai has developed a perfect framework that combines life and art into a daring and politically charged performance that helps define how we see modern China. He infuses his sculptures, photographs, and public artworks with political conviction and personal poetry, often making use of recognizable and historic Chinese art forms in critical examinations of a host of contemporary Chinese political and social issues and to connect tradition with contemporary social concerns.

These aforementioned artists are only but a few redefining art in contemporary society by creating new personal art coefficient in unique formalisms that help deconstruct the complexities of contemporary existence, and link the present to the past. But their art only represent a small variant of the conceptualism of contemporary artistic expressionism. A new creative idiom sit parallel to this - one defined by complex appropriation and the philosophy of relational aesthetics. Artists cut across various continents have since the end of postmodernism began developing art defined by the intersection of traditionalism and contemporaneity leading to the creation of art that bridges various centuries and decades as well as art genres and cultures. Their art contributes to the innovativeness of contemporary artistic expression by defining a new creative movement of relational aesthetics in Twenty-first Century art-space. 


\section{Relational Aesthetics the New Philosophy of Contemporary Art}

Artists are looking for a new modernity that would be based on translation. What matters today is to translate the cultural values of cultural groups and to connect them to the world network. This 'reloading process' of modernism according to the twenty-first-century issues could be called Altermodernism, a movement connected to the creolisation of cultures and the fight for autonomy, but also the possibility of producing singularities in a more and more standardized world (Bourriaud 1998: 76).

In his widely read book Relational Aesthetics 1998, Nicolas Bourriaud succinctly captures the emergence of a new modernism in contemporary art define by cultural revivalism and re-contextualization. First he argues that there is no past, present and future in art but that art exist in a timeless frame that dismantles time and periodic boundaries. His argument is underpinned by his observation that art constantly appropriates itself with each reprise consisting an extension of the original that creates new dialogues defined by different cultural and societal context. Thus, there are elements of the past, present and futuristic projections in constant artistic interactions. Bourriaud particularly finds this relational artistic coefficient consistent with contemporary artists. There is a tendency since the inception of contemporary art for artists in different regions to return to their cultural roots to revive and re-invent cultural forms as leitmotif for the creation of unique new conceptual art forms. This contemporary creative approach has a large following, thus, resulting in a new contemporary art movement Bourriaud refers to as 'Altermodernism'. This new movement is driven by culture and fosters three main ideologies: firstly the translation of cultures to connect to world network. This involves the deliberate appropriation of indigenous cultural forms by many artists as a way of modernizing traditionalism into forms with contemporary values and identity. Secondly the creolisation of cultures through cultural reloading and hybridization leading to the emergence of new ones. And thirdly cultural appropriation to create new singularities, distinct artifactuality and unique personal art coefficients. These three main philosophies define the movement of Altermodernism Bourriaud alludes to, and all artists engage in this contemporary creative revolution are linked by a shared consciousness define by cultural revivalism through appropriation and re-contextualization of known cultural values and visual culture into unknown new realisms. This is what Bourriaud refers to as relational aesthetics, when a "set of artistic practices take as their theoretical and practical point of departure the whole of human relations and their social context, rather than an independent and private space". (Bourrriad 1998: 41). To best understand Bourriaud's theory, a detailed look at the works and practices of some contemporary artists and designers from various cultures whose practices are defined by the re-invention of indigenous cultures in contemporary art-space is necessary.

\section{Cultural Translation and Re-contextualization in Contemporary Art}

The unique practices of contemporary artists such as George Nuku, Sukanthy Egharevba and Clement Akpang provide visual valorization to Bourriaud's theory of relational aesthetics and his views that art is timeless. Sri-Lankan-born-Nigeriabased painter Sukanthy Egharevba engages the traditional in unique approaches informed by the philosophy of Natural Synthesis propounded by Uche Okeke and the Zarianists. She juxtaposes the unique complex fluid geometricism of Tamil Kolam with the symbolic qualities of Tiv traditional graphic systems in the creation of unique abstract paintings celebrated for their distinct visual configurations and hybrid qualities. In Sri-Lanka, Tamil Kolam design "expresses a dual language; that of silence and humility, and of symbolic writing, the gate which opens to the realm of imagination" (Hari 1974, 56-57). Sukanthy explores these unique qualities of expressiveness in Kolam design, its symbolism and structures of writing as leitmotifs in her contemporary paintings. She engages in a complex appropriation in which rather than mimicking traditional Tamil Kolam designs verbatim, its elements are rather adapted as motifs for creating new visual imageries infused with recognisable elements of Tamil and Tiv pictorial elements but all re-invented in new forms. In this sense, the visual qualities rather than the symbolic meanings are crucial to the artist and in re-inventing such visual qualities she further advances and re-contextualizes the traditional purpose of Tamil Kolam design as decorative drawings and paintings to adorn the entrances of courtyards, homes, business centres and temples, in new contemporary frameworks. Another key element the artist appropriates from traditional Kolam designs is its derivation of design concepts and motifs from nature. This embrace of nature friendly designs and motifs also informs her association with and appropriation of traditional Tiv cultural graphic systems predominantly composed of nature-inspired symbols and ideographs. From the Tiv ethnic group, the artists explores traditional ideographs and body scarification such as OO Man Iyo, Ikondo, Tsonka, Okpoto etc., in distinct pictorial compositions. These non-verbal communicative and aesthetic expressions used mainly as human body adornments, on the walls of mud houses, textile designs, wood carvings, calabash decorations, pottery, traditional furniture and architecture are explored by the artist in new forms of abstract painting. She also explores the metaphysical qualities associated with Tiv pictorial elements which are deeply rooted in folklore and other cultural experiences and designed to provide socio-cultural stability and harmony amongst the people. Through a painterly methodology akin to musical performance, Sukanthy orchestrates a unique hybridization of Sri-Lakan Tamil Kolam and Nigeria Tiv traditional ideographs adapted in new creative ways that results in hybrid compositions that defy cultural limitations to celebrate multiculturalism.

Her paintings are done using acrylic colour medium. This enables the artist to manipulate colours, design motifs, figures and the space around them in such a way that best projects the message of the painting. This compositional technique allows for an expression of sublimity in her art. Her paintings such as 'Season of Festivities 2010' and 'Pangs of Womanhood 
2010' exemplify this complex juxtaposition of cultural diversity in a conceptual interpretation of cultures in new aesthetic idioms that chime with the movement of Altermodernism in contemporary art. 'Season of Festivities 2010' (fig.1) is a mixed media painting made up of perspex, white ropes, and buttons of various colours and sizes. It is a non-figurative abstraction defined by bright colours and divided into three parts by its visual configuration. It combines a complex sense of fluidity in the bottom, top left and middle sections of the painting contrasted by a rigid structure that punctuates this lyrical composition at the top right corner. The top portion of the painting is treated with dark hues while the lower portions are highlighted with bright colours. This painting has a dominance of red colour hue with few shades of yellow and blue, creating an interesting colour harmony. Acrylic colours, which gives brilliancy and transparency to the pictorial motifs, are used. Circles and dots, which are prominent features of both Tamil and Tiv cultures, are employed as part of the mixed media elements. Triangles, squares and other pictorial designs are used to embellish the background.

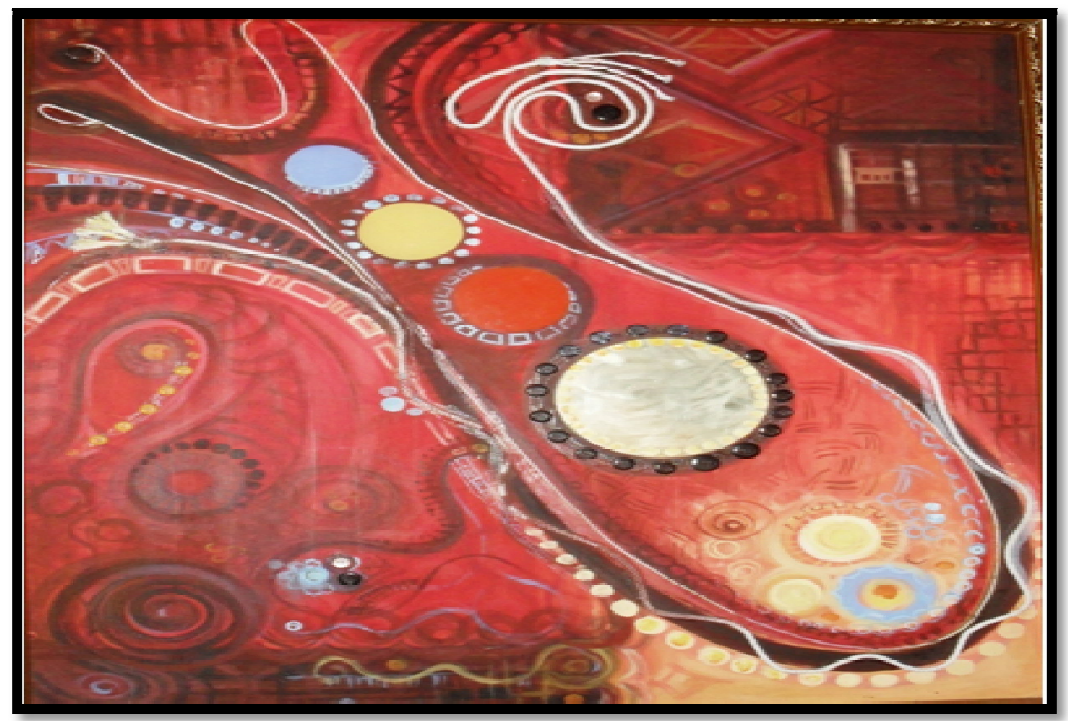

Figure 1: Sukanthy V.E. Seasons of Festivity 2010, Mixed Media with Perspex, 83cm X 98cm, ( Source: The Artists)

The context of the painting describes a particular period of the year when the communities gather for different cultural festivals. Indigenes of Tamil and Tiv cultural communities travel back home to participate in different celebrations. This painting is a conceptual representation of the climax of the moods in one of these festivals. The different shades of red and yellow colours, and their nuances, are used to represent the euphoria, and energy/joy people experience during such celebration.

Another painting which shares this ethos of cultural hybridism is 'Pangs of Womanhood 2010'.

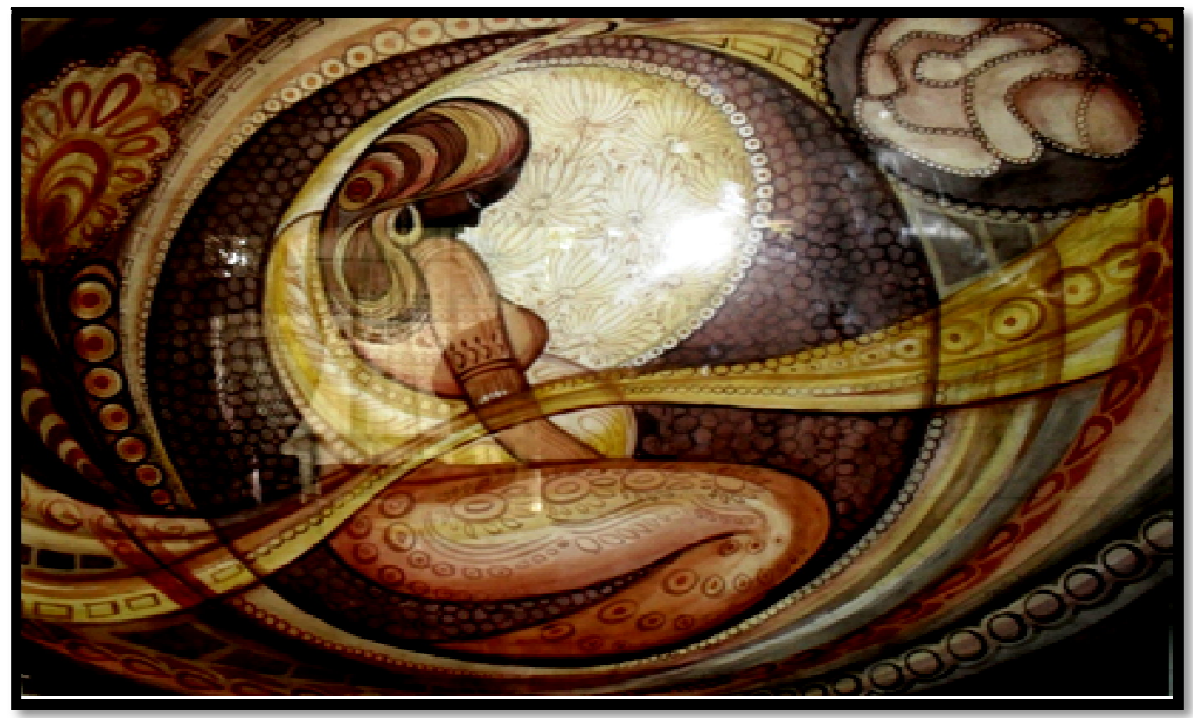

Figure 2: Sukanthy V.E. Pangs of Womanhood 2010, Water Colour on Paper, $84 \mathrm{~cm}$ X $67 \mathrm{~cm}$, (Source: The Artist) 
This painting is lyrical in its conception and fluid in its visual character. Circles, dots and curvilinear lines derived from both Tamil and Tiv art, but modified to suit the picture prospect, form the basis of the entire composition. The colour scheme is dominantly neutral because the painting focuses on the travails of womanhood. The context of the painting attempts to capture and interrogate the array of stress and pains women endure during pregnancy. In this water colour painting, circles of different sizes are used to encapsulate both the central object of a semi-abstracted or stylized figure of a squatted pregnant woman, and a suspended image of a developing child in the womb. The closeness of both figures and connecting circles are used to symbolize the relationship between a woman and her unborn child. The contrast adopted using bright and dark colours represent mood swings during the period of expectancy. Sweeping lines of different sizes and lengths, extending to the lines that cut across the middle of the circle, are used to represent the uncertainties and lack of control over the pregnancy. Both Tamil and Tiv motifs are employed as decorative patterns in the work. Bright and dark shades of colours, in monochromatic grading from yellow to umber are extensively used to reinforce the three dimensional qualities of the figure and the ambience of the theme explored.

Sukanthy's appropriation of design elements traditional to both cultures, Tamil and Tiv, has synthesized two cultural entities into a single creative language which assumes a universality hardly traceable to any of the groups. The idea behind the use of stylization as a visual idiom in her works is to allow for the manipulation of the known figure within previous knowledge of skills of intellectual painting ability, into a new unknown contemporary context of aesthetic hybridization and translation. The artifactuality of these paintings defined by appropriation indicates a sense of cultural/ aesthetic juxtaposition achieved through cultural intersection of the Tamils of Sri-Lanka, Asia, and the Tivs of Nigeria, Africa. This captures a sense of multiculturalism in the arts that both fosters cultural interactions, but also advance cultural uniqueness within that multiculturalism. Her works are, therefore, an artistic confluence that valorises Bourriaud's theory of relational aesthetics and the timelessness of art.

George Nuku is a Maori artist who is engrossed in the art of cultural revivalism define by eclectic expressionism. Nuku's trenchant pursuit of cultural re-invention has defined not just his art but also his life as he declares that "it was not me carving them (artworks), but the repetition of their carving, that gave me a way of life...the rules for art are the rules for life" (Nuku quoted in Godreche 2012: 2). His art centres on Maori culture especially its pictorial elements of body painting and scarification with a view of re-inventing them to create a new language and identity. He is New Zealander with Ngati Kahungunu and Ngati Tuwharetoa tribal affiliation through his mother and his art reflects these cultural influences as seen in his focus on culture, theology, ideology, and philosophy of ancestors. He re-invents the traditional and known, to new unknown but recognisable forms to create new dialogues and visual narratives to change European construed narratives about Maori native people and culture as exotic and noble savages. He declares that his role as a contemporary artists is to engage those dialogues by transforming the traditional in new contemporary ways that are conceptual and contemplative. ${ }^{1}$

Nuku has developed the philosophy of Contemporary Ethnographic as the conceptual framework of his new found creative ethos. His focus is on Maori tattoos (moko) pictorial elements and visual configurations because tattoos form part of Maori's cultural identity currently threatened with extinction as result of European anti-indigenous civilization. Nuku declares that,

Tattoos are, as we say globally hot. Locally not...The moko (traditional tattoo) wears you, and helps you, it informs you about your conduct, the way you speak, your behaviour, to be generous and understanding. That is what creates bridges between people; and I wish to connect with people, to grow, to continue to learn. The job of the artist is to create a true reflection of life now: that is why I use polystyrene, a material of this time. My ancestors came in a world of trees, and did everything from the trees: houses, canoes. We continue to use it, but we do not live in a world of trees anymore! Ours is a world of plastic. So looking at plastic, you look at yourself (Nuku 2012: 1).

Nuku argues that art plays a central role in contemporary society when tailored towards Contemporary Ethnographic for cultural revivalism and promotion. The advancement and re-invention of indigenous visual culture in contemporary art expression is believed to constitute a framework for preserving cultural identity in the face of aggressive globalism and for correcting negative narratives and stereotypes. Nuku holds dear to this ideology and the opinion that such cultural reinvention creates relational aesthetics that bridges the past with the present, thus, leading to the Altermodernism promulgated by Bourriad. This role of translating indigenous cultural forms into contemporary visual idioms is considered by Nuku the mandate of all contemporary artists as a way of re-inventing societies and ensuring development rooted in cultural frameworks. Artists he observes represent the antidote to the globalization of mediocrity and are to use their art to create a divine communication of human nature with nature by traveling always between the inside and the outside, because such inbetween spaces holds the potency for the creation of new culturally defined and unique art forms and genres in contemporary society.

\footnotetext{
1 The British have a romanticized view of us due to the conduct of the Maori soldiers during the wars, and combined with the propaganda of the nation building machine. It is complex and paradoxical. In France, it is more exoticized: We are seen as noble savages, powerful indigenous people! And our cousins from French Polynesia are seen as exotic beautiful flowers! The role of people like myself is to improve those perceptions: We are a vibrant, living, dynamic culture. We are not dead, and in museums! We are facing our past, but also our future. Godreche, D. (2012). 'George Nuku: A Maori Sculpture in Paris', Indian Media Network Logo [Online] Available on: https:// newsmaven.io/ indiancountrytoday/ news/ george-nuku-a-maori-sculptor-in-paris/ August 12.
} 
His works reflects this creative ethos. The installation Waharoa/ Portal: Te Ao Marama - The World of Light 2013, provides visual cues to the artist thinking with regards to culturally inspired contemporary expressionism which he refers to as Contemporary Ethnographic, succinctly captured in the exhibition artist statement.

Don't worry, it will be traditional by this afternoon...this artwork's shape and elements are dictated by its site, availability of materials, and time; these are some of the factors that determine a given tradition. I say that it is a traditional practice to be innovative. The composition of Waharoa speaks to the ancestors and forces of nature that are present in this Great Hall. The plexiglass as a material speaks to light and the water that surrounds us; they are the source of life itself. The abalone shell and the white feathers speak directly to the wood that surrounds us - the union of earth, sea and air. The red and black paint, and the cord binding everything together, represent time/ space and male/ female aspects respectively. The Waharoa communicates to the people that the past is in front of us and the future we remember (Nuku 2012: 1).

The installation from his artist statement makes several connections between the mundane and the metaphysical, human and nature, elements of the environment and between the past, present and future all roped into an installation to visually articulate their relationship and connectedness. The composition is intriguing as a result of its complex visual configuration. It is a fascinatingly lyrical flow of geometricism adapted from Maori moko and other body markings and painting to create unique forms that are traditional and contemporary at the same time. Nuku adopts the parlance of minimalism, site-specificity, the activation of space etc., in this installation, thus, achieving a more perfect embodiment of simplistic and symbolic abstractionism new to the contemporary artworld.

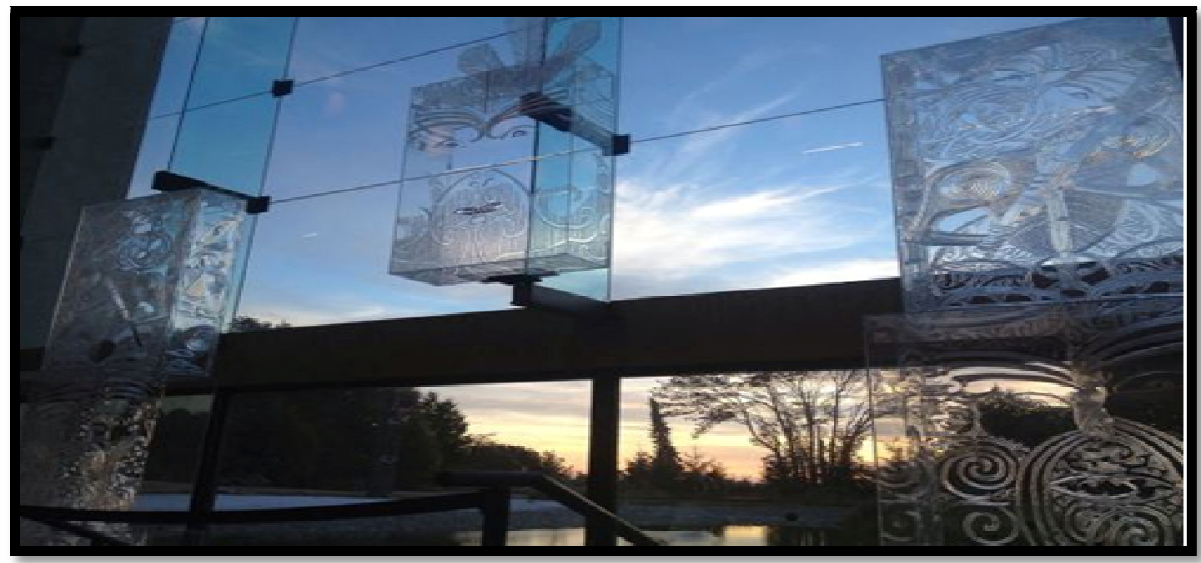

Figure 3: George Nuku. Waharoa/ Portal: Te Ao Marama, the World of Light, 2013 Source: Indian Country Today Network

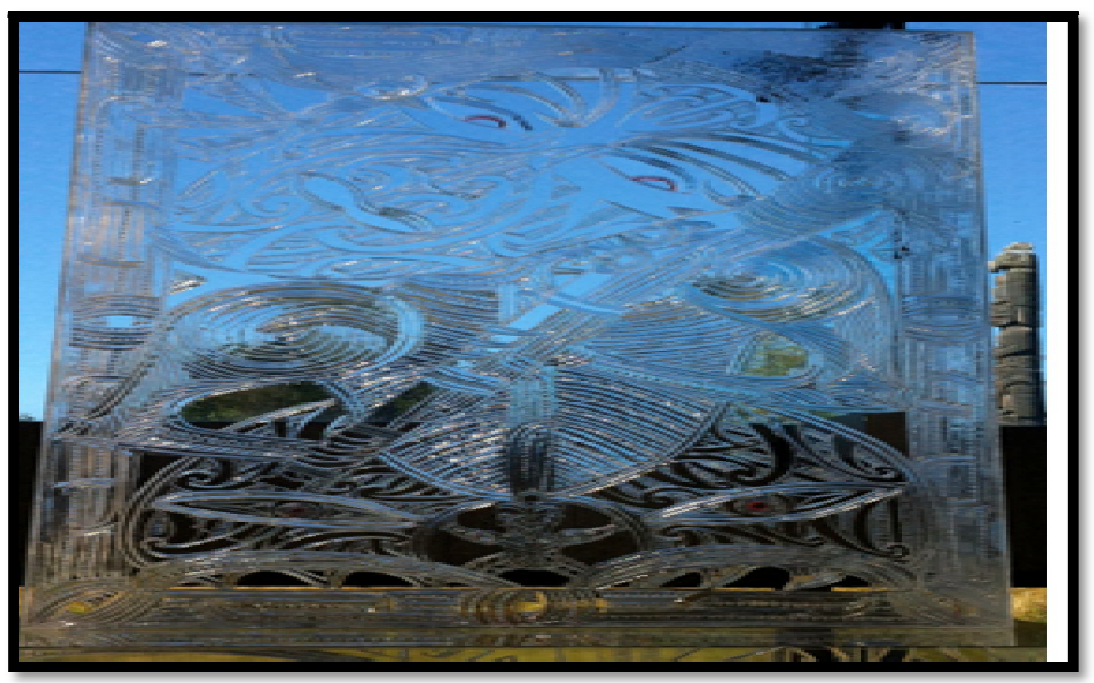

Figure 4: George Nuku. Waharoa/ Portal: Te Ao Marama -

The World of Light, 2013, Close-Up

Source: Indian Country Today Network

The works of contemporary postcolonial artist and designer Clement Akpang provides another variant of the creation of new distinct art coefficient in contemporary art-space through appropriation. His art explores the boundaries between art 
and design as well as those between primitivism and contemporaneity. The exploration of in-between spaces between the aforementioned, provide critical creative frameworks that open possibilities of creating art that exist outside all established genre categorization. Define by the philosophy of appropriation which is consistent in his sculptures and print designs, is a focus on re-defining culture in contemporary context by re-contextualizing the indigenous or primitive into modern realisms. This visual translation of traditional forms into contemporary ones is a creative reflection of Bourriaud's theory of Altermodernism. Clement's works destabilizes established aesthetic constructs by his critical interrogation of aesthetic parameters of established art genre and cultural forms as a point of creative departure for the creation of new ones. The new interstitial art he invents and its unique artistic language using this critical methodology, deconstructs traditional art definitions and contributes to debates that argue against the categorization of contemporary art based strictly on known genre parameters, which only impede understanding and appreciation of the diverse formalisms that the chaotic multiculturalism and globalism in contemporary society gives rise to. His installation of prints titled 'New Realisms 2016' exhibits the artist's conscious appropriation and modernization of supposed primitive ideographs and traditional graphic systems from Nsukka, Bantu, Ashanti, and Zulu cultures in Africa to deconstruct ideological and cultural subjectivities. His art framed in cultural revivalism ideologies assumes a slightly avant-garde character by his use of such hybrid art formalisms to create counternarratives to those of Europe about indigenous Africa and African cultural idiosyncrasies.

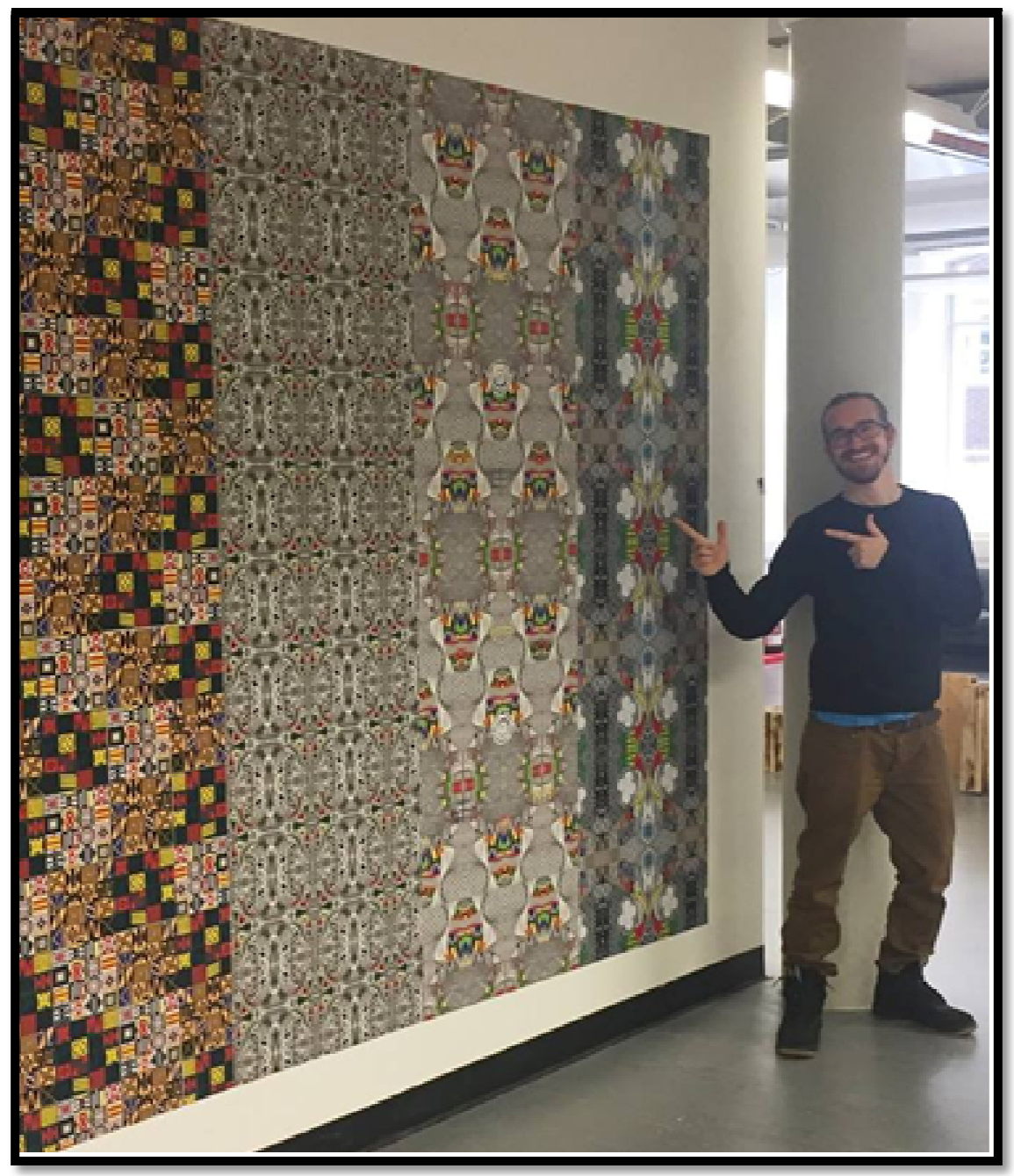

Figure 5: Clement Akpang. New Realisms 2016 (Uob We Create Together)

By intersecting and hybridizing various cultural visual idioms, the artist's works challenges long held perceptions about art, design and aesthetics. Firstly it challenges the categorisation of primitivism/ traditionalism and contemporaneity in art. 'New Realism 2016' composed of seven separate large print designs juxtaposed into one homogenous print-art, is a unique intersection of periods and visual idioms into a new contemporary art formalism. This piece is created through the appropriation, re-contextualization and re-inventing of primitive/ traditional African ideographs and symbols used in premodern society as marks of tribal/ community identification, into contemporary art. Traditional African ideographs of Insibidi, Uli and Adinkra are composed and recomposed into a plethora of leitmotifs, then using African colour scheme of earth colours, each composition are further explored with desired visual effects repeated into patterns that make up the these large scale prints. The pre-modern associations of these appropriated ideographs with traditional body/ wall paintings and religion often 
result in their classification as primitive, but this pieces provides a new artistic dialogue by re-contextualizing such supposed primitive ideographs into contemporary print designs, thereby altering their context, and ascribing to them new meanings, forms, and reception as new realisms. This installation of print pieces, thus, represents a complex intersection of periods - it exist in-between traditionalism and contemporaneity as both print art, digital art and painting; thus, it challenges and deconstructs what is considered primitive and that which is canonised as modern/ contemporary. This contemporary reinvention and re-contextualization of pre-modern African graphic systems, bridges in artistic sense the gap between the past and present; as Nicola Mansell (2017) points out, "It is clear that Clement blurs the lines between the past and the present, providing a powerful connection to both primitivism and modernity and everything in-between" (Mansell 2017: 1). Most importantly, this connection of the past with the present, primitive and contemporary in Twenty-first Century artistic expressionism provides a valorisation of the theory of relational aesthetics and contributes to debates about a new movement in contemporary art which Nicolas Bourriaud refers to as Altermodernism.

\section{Conclusion}

The ideologies of cultural revivalism in contemporary art is consistent in the works of the aforementioned contemporary artists and many others. The methodologies of adaptation, experimentation, appropriation and recontextualization sits at the base of their distinct individual practices. Whilst the medium of expression in terms of materiality, and mechanism of artistic production in terms of style may differ, their deconstruction and re-invention of appropriated indigenous pictorial elements in new contemporary ways defines a new creative idiom that preens both traditionalism and contemporaneity in order to advances cultural longevity in the face of global anti-cultural civilization. Their approaches to contemporary expression which bridges art genres and interlaces traditionalism in contemporary art, further deconstructs aesthetic, cultural and periodic boundaries. The works are an expression of Contemporary Ethnographic, thus, bridges the gap between primitive cultures and contemporary civilization. In this sense, their works reflects Bourriaud's arguments of the existence of a new movement in contemporary art-space which he refers to as Altermodernism involving the translation and re-translation of cultures through art and design using studio practice to revive and propagate cultural identities and heritage in contemporary society. Using indigenous cultural forms as impetus for developing leitmotifs for contemporary art, these artists have successfully developed new personal art coefficients, a new ethos/ direction, which a critical mass could follow as contemporary art continue to evolve and stir more critical dialogue on society, culture and globalization.

\section{References}

i. Bourriaud, N (1998). Esthétique Relationnelle. Les Presses du réel, Dijon.

ii. Ellsworth-Jones, W. (2013). 'The Story Behind Banksy' Smithsonian Magazine February, pp.2

iii. Godreche, D. (2012). 'George Nuku: A Maori Sculpture in Paris', Indian Media Network Logo [Online] Available on: https:/ / newsmaven.io/ indiancountrytoday/ news/ george-nuku-a-maori-sculptor-in-paris/ August 12.

iv. Hari, R. (1974) 'Powder Patterns', Madras Christian College Magazine, 43.

v. Mansell, N. (2017). 'Clement Emeka Akpang: Contextual Week Lecture on Globalism from Diaspora Perspectives', WeCreate Together [Online] Available at http:/ / www.blogs.wecreatetogether.net/ nicolamansell/ 2017/ 01/ 04/ clement-akpang/

vi. Smith, T. (2009). What is Contemporary Art? Chicago: University of Chicago Press.

vii. Tate Modern (2010) 'Contemporary Art' Tate Modern [Online]. Available at: https:/ / www.tate.org.uk/ art/ artterms/ c/ contemporary-art 